Research Square
Preprints are preliminary reports that have not undergone peer review.

They should not be considered conclusive, used to inform clinical practice, or referenced by the media as validated information.

\title{
Can We Predict Turnover Intention in Nursing Students? An Exploration of the Relationship Between Resilience, Burnout and Their Relationship with Future Turnover Intention
}

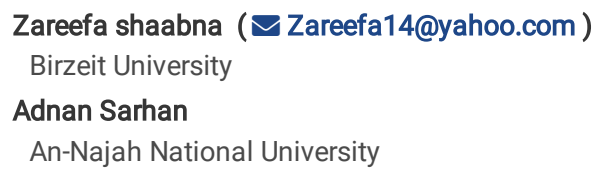




\section{Abstract \\ Introduction:}

Globally nursing is deemed a demanding profession. Recently, attention has been placed on the psychological well-being of employed nurses. Since nursing students are the future of the nursing workforce, it is essential to advance our understanding of the role of resilience in decreasing burnout and future turnover intention in nursing students.

\section{Aim}

The study aimed to assess the levels of resilience and burnout, examine the relationship between the two measures, and to determine the relationship between the two measures with future turnover intention and participants' demographics.

\section{Methods}

A cross-sectional descriptive correlational study was conducted using an online survey on 409 undergraduate nursing students from three large nursing institutions in West Bank-Palestine. The study used The Connor-Davidson Resilience Scale (CD-RISC 10), The Burnout Scale, and a demographic data sheet.

\section{Results}

Moderate levels of resilience and burnout were found among the participants. The analysis revealed a negative correlation between resilience and burnout ( $r=$ -0.35). In addition, the study findings showed that almost half of the students (46.9\%) were not satisfied with their major when they joined the nursing program, and half of the students (50.1\%) intended to leave nursing profession in the future. In this study, higher resilience was associated with male gender, wanting to study nursing, playing exercise/sports, working, living on campus, receiving support from friends and family, intention to stay in the nursing profession, and studying for a week or more of the exam. Whereas not receiving support from family \& friends, not exercising, smoking, intend to leave nursing profession, higher academic level, lower GPAs, studying an hour or less daily, and studying in a day or less of the exam were all associated with higher burnout.

\section{Conclusion}

Resilience in nursing students might play an important role in decreasing global nursing shortage by enhancing academic success and decreasing future intention to leave and burnout.

\section{Background}

The obligations and the physical and psychological demands innate in nursing work have been associated with vulnerability to burnout [1, 2]. A psychological state characterized by emotional exhaustion and withdrawal from one's job (cynicism) [3]. Abundant studies have focused on burnout among health students, mainly nursing students $[4,5,6]$ and the levels of burnout revealed are alarming since this syndrome can disrupt professional growth, compromise patient safety, and have serious consequences on student's physical and mental health, such as sleep disturbances, depressive symptoms, suicidal ideation, and drug use $[7,8,9]$.

On the other hand, Nursing turnover is an abstraction that involves everything from resigning or transferring within a healthcare organization to leaving the profession as a whole [10]. Turnover intention is deemed as one of the struggles that several health-care organizations face, leading to inadequate nurse staffing, elevated work stress, and job dissatisfaction [11, 12]. Among the many interrelated factors that impact why nurses in common intend to leave the profession, burnout is one that has frequently been found [13,14]. Turnover intention was widely studied in nursing; however, few studies were carried on nursing students. In a Swedish population-based study of three separate cohorts $10 \%$ (in two cohorts) and $20 \%$ (in the third cohort) of new graduates strongly intended to leave the profession one year after graduation [15]. Kovner and Djukic [16] have reported that in the United States more RN graduates left their first nursing job (26\%) than nursing profession (2\%) during the first two years in career. In South Korea, it was found that $17.6 \%$ of the nursing students had turnover intention within 2 years of employment [17].

Individuals' resilience is defined as their capacity to bounce back or cope well with stress when faced with adversity, especially when recovering from extremes of trauma, deprivation, danger, and severe disturbance [18, 19]. Cyrulnik adds that resilience is an individual's, 'ability to succeed, to live and to develop in a positive way despite the stress or adversity that would normally involve the real possibility of a negative outcome' [20]. Empirical evidence demonstrates that resilience enables individuals to cope successfully and recover quickly from adverse circumstances [21]. Results from epidemiological studies showed that in nursing, resilience is an important attribute of a nurse to survive and adapt to stressful working environments, optimize personal ability and establish supportive systems [22, 23]. Literature showed that resilience was negatively associated with turnover intention and burnout. Alameddine et al., [24] in his study in Lebanon revealed that Nurses' resilience was positively associated with job satisfaction and negatively associated with intention to quit and exposure to violence. Whereas Guo et al. [23] in his study on 1,061 Chinese nurses revealed that a lack of resilience was a strong predictor of burnout ( $r=0.2-0.4$, p.001), and low levels of individual resilience was found to be associated with higher levels of emotional exhaustion, cynicism, and reduced professional efficacy. Similarly, Kutluturkan et al., [25] in his study discovered a negative relationship between resilience and burnout. 
International and national studies have been conducted to investigate the relationship between resilience and burnout in nursing; however, few studies were carried out on nursing students and even fewer studies investigated turnover intention in undergraduate nursing students. Therefore, the aim of this study is to investigate the relationship between burnout and future turnover intention with the mediating effect of resilience.

\section{Methods}

\section{Study Design and Setting}

This cross-sectional descriptive correlational study was conducted among undergraduate nursing students from different academic years in West BankPalestine. In order to consider the sample from different representative areas of the West Bank with varying demographic backgrounds that reflected the nursing student population as a whole. The setting for this study included three large universities. From the South-Bethlehem University; from the middleBirzeit university; from the North- An najah National university.

\section{Participants and Sampling}

The sample size for this study was calculated based on $95 \% \mathrm{Cl}$ and $5 \%$ margin of error by using the Raosoft sample size calculator, and the recommended sample was 320 participant. All students within the baccalaureate nursing program from the mentioned nursing universities were given the opportunity to participate in the study.

\section{Instruments and Data Collection}

Three instruments were used in this study: The Connor and Davidson Resilience Scale (CD-RISC 10) was used to measure resilience, The Burnout Scale was taken from the Professional Quality of Life Scale Version 5 (ProQol5) to measure burnout, and a demographic data sheet developed by the primary researcher was used to gather demographic data. High reliability, stability, and construct validity of the three measures have been confirmed in different studies. The Arabic versions of the three instruments were chosen because the study participants were proficient in Arabic and the measures were validated in the Arabic language.

Institutional Review Board approval was obtained from An-najah National University prior to data collection. A pilot study was conducted on $5 \%$ of the sample size $(n=16)$ of undergraduate nursing students to determine the clarity of the questionnaire, and to estimate the time needed. Furthermore, the internal consistency for the scales was measured using the Cronbach's alpha. The scale analysis revealed a Cronbach's alpha 0.937 for resilience, and 0.759 for the burnout measure. Overall, the final survey appeared to be well-designed, easy to score, easy to interpret, and require less than 10 minutes to be filled. Due to the COVID-19 pandemic and the transition to online learning, it was difficult to reach all nursing students manually. Therefore, in order to give an equal opportunity to all nursing students to participate in the study, the researcher e-mailed the three universities to participate in the study after explaining the necessary details, and after the universities agreed to participate in the study, the researcher mailed the link of the electronic survey to the universities, and they distribute the questionnaire electronically through university portals, and the data was collected from $31^{\text {st }}$ May-29 ${ }^{\text {th }}$ June 2021.

\section{Data Analysis}

After completed surveys were reviewed for missing data, the data were analyzed using the IBM SPSS Statistics version 28. Descriptive and inferential statistics such as Pearson correlation test was used to determine relationship between the two variables resilience, and burnout. Independent samples t-test, analysis of variance (ANOVA), and post hoc analysis were used to determine the relationship between the demographic variables and main variables of the study.

\section{Results}

\section{Sociodemographic characteristics}

A total of 409 nursing student completed the study survey. The socio-demographic profile of the participants is shown in Table 1 . The majority of the participants were female students $68.2 \% .46 .9 \%$ reported they did not want to study nursing when they joined the university, and $50.9 \%$ reported they not view themselves working in nursing in the future and intend to leave nursing profession at a point of their lives.

Table 1: Participants' Demographics 


\begin{tabular}{|c|c|c|}
\hline Independent Variables & The type of Answer & Frequency (\%) \\
\hline \multirow[t]{4}{*}{ The university that the student is enrolled at } & An-Najah National University & $220(53.8 \%)$ \\
\hline & Birzeit University & $133(32.5 \%)$ \\
\hline & Bethlehem University & $56(13.7 \%)$ \\
\hline & Total & $409(100 \%)$ \\
\hline \multirow[t]{4}{*}{ Academic Year } & First & $131(32 \%)$ \\
\hline & Second & $98(24 \%)$ \\
\hline & Third & $89(21.8 \%)$ \\
\hline & Fourth & $91(22.2 \%)$ \\
\hline \multirow[t]{3}{*}{ Gender } & Male & $127(31.1 \%)$ \\
\hline & Female & $279(68.2 \%)$ \\
\hline & Prefer not to answer & $3(0.7 \%)$ \\
\hline \multirow[t]{6}{*}{ GPA (Grade Point Average) } & $A(88-100)$ & $44(10.8 \%)$ \\
\hline & B (80-87.9) & $116(28.4 \%)$ \\
\hline & B- $(76-79.9)$ & $110(26.9 \%)$ \\
\hline & $C(70-75.9)$ & $83(20.3 \%)$ \\
\hline & C- $(65-69.9)$ & $48(11.7 \%)$ \\
\hline & Less than C- & $8(2 \%)$ \\
\hline \multirow[t]{2}{*}{ Wanted to study nursing when I joined the study (satisfied) } & Yes & $217(53.1 \%)$ \\
\hline & No & $192(46.9 \%)$ \\
\hline \multirow[t]{2}{*}{ I see/ view myself working in the nursing profession all my life } & Yes & $201(49.1 \%)$ \\
\hline & No & $208(50.9 \%)$ \\
\hline \multirow[t]{2}{*}{ Smoking cigarettes or hookah } & Yes & $123(30.1 \%)$ \\
\hline & No & $286(69.9 \%)$ \\
\hline \multirow[t]{2}{*}{ Doing Sports/ Exercise } & Yes & $204(49.9 \%)$ \\
\hline & No & $205(50.1 \%)$ \\
\hline \multirow[t]{2}{*}{ Working while studying } & Yes & $128(31.3 \%)$ \\
\hline & No & $281(68.7 \%)$ \\
\hline \multirow[t]{2}{*}{ Living in Campus/ Dorm } & Yes & $83(20.3 \%)$ \\
\hline & No & $326(79.7 \%)$ \\
\hline \multirow[t]{2}{*}{ Receiving support from family and friends } & Yes & $307(75.1 \%)$ \\
\hline & No & $102(24.9 \%)$ \\
\hline \multirow[t]{4}{*}{ Average daily study hours } & An hour or less & $119(29.1 \%)$ \\
\hline & 2-3 Hours & $138(33.7 \%)$ \\
\hline & 4 Hours & $75(18.3 \%)$ \\
\hline & More than 4 Hours & $77(18.8 \%)$ \\
\hline \multirow[t]{3}{*}{ The method usually used to prepare for an exam } & Start Studying a week or more before the exam & $66(16.1 \%)$ \\
\hline & Start Studying days before the exam & $223(54.5 \%)$ \\
\hline & Start Studying a day or less before the exam & $120(29.3 \%)$ \\
\hline
\end{tabular}

Note. This table reviews the participants' demographics (Frequencies and Percentages); university, academic year, gender, GPA, wanted to study nursing, viewing self-working in nursing lifelong, smoking, exercise, working, residence, receiving support, daily study hours, and method used to prepare for an exam Levels of and Correlation Between Resilience and Burnout 
The mean of resilience was (28.51), and the standard deviation was (6.72). 202 (49.4\%) had average levels, 39 (9.5\%) had low levels, whereas 168 (41.1\%) had high resilience levels. The mean of burnout was (25.32), and the standard deviation was (6.92). 209 (51.1\%) had average levels, 113 (27.6\%) had low levels, whereas $87(21.3 \%)$ had high levels of burnout.

The Person Correlation analysis revealed an inverse correlation between burnout and resilience $(r=-0.35)$.

\section{Significant Differences in Resilience and Burnout}

The results showed that being a male $(p=0.040)$, wanted to study nursing when joined the university $(p=0.008)$, intend to stay in the nursing profession in future $(p=0.001)$, playing exercise $(p=0.001)$, working $(p=0.005)$, living in campus $(p=0.024)$, receiving support from friends and family $(p=0.001)$, and start studying a week or more of the exam $(p=0.001)$ were associated with higher resilience with significant differences.

Regarding the burnout measure, the results showed that students who play exercise $(p=0.001)$ and receive support from their friends and family ( $p=0.001)$ had lower burnout with significant differences. In comparison, students who were males $(p=0.003)$, smokers $(p=0.001)$, students intend to leave nursing profession in future $(p=0.001)$, higher academic year (third- and fourth-year students) $(p=0.015)$, low GPA $(p=0.027)$, study an hour or less on a daily basis $(p=0.007)$, and start studying a day or less of the exam $(p=0.001)$ were associated with higher burnout with significant differences.

\section{Discussion}

The results showed that most of the participants had an average resilience scores. The mean of resilience in this study was similar to the mean of resilience in 194 Indian students, which was $26.31 \pm 6.28$ [26]. However, the mean of resilience in this study was low compared to other studies that used the same measure. For example, the mean of 240 nursing students from Australia was (37 \pm 7 ) [27], the mean of 439 nursing students from Saudi Arabia was (32.26 \pm 5) [28], and over $81 \%$ of nursing students sample in Egypt were highly resilient [29]. As a result, the findings of this study may be attributed to the stressful academic and clinical environment in Palestine, especially since the data was collected during the COVID-19 pandemic.

This study revealed that the participants had average level of burnout, whereas $21.3 \%$ of the sample had high level of burnout. The high level of burnout in this study is concerning compared with the findings in other studies. Abram \& Jacobowitz [30] found that the mean of burnout using the same measure was 23 in 119 nursing students from the US. Lopes \& Nihei [31] found that $6 \%$ of 284 nursing students from Brazil presented high burnout. Quina Galdino et al., [32] found that $10.5 \%$ of 114 nursing students from Brazil had indicative of burnout syndrome. The burnout in this study was considered high compared with burnout in registered nurses working in Arabic and surrounding countries. Alshawish \& Nairat [33] found that the prevalence of burnout was $10.6 \%$ among 207 nurses and midwives working in the Palestinian governmental primary health care centers in the north of the West Bank. In addition, Al Barmawi et al., [34] found in their study in Jordan that most nurses had low burnout. However, higher burnout compared to those in our study was found in a longitudinal survey by Rudman \& Gustavsson [35] who revealed high burnout in Swedish nursing students (from 30-41\%) across three years in higher education. An increase in depressive mood and less fulfillment with life, arising stress in academic, clinical, and personal life, online learning, and the consequences of the Covid-19 pandemic can be attributed to the high level of burnout.

The findings in this study revealed an inverse correlation between burnout and resilience $(r=-.35)$. This finding is congruent with the findings in previous literature in which burnout negatively correlated to resilience $(r=-0.55, p<.01)$ (Rios-Risquez et al. 2016), $(r=-0.472, P<0 \cdot 001)$ [27], $(r=-.486, p<.01)$ [36].

The unfortunate findings in this study revealed that almost half of the students were not satisfied when they joined the nursing program, and half of the students intend to leave nursing profession in the future. On the other hand, students who intend to stay in the nursing profession had higher resilience and lower burnout. According to Flinkman et al., [37] literature review, nurses' intention to leave the profession varied from 4-54\% across international studies. A study conducted in South Korea by Kim et al., [17] revealed that $17.6 \%$ of 3rd and 4th nursing students had turnover intention within two years of career. Additional study in China revealed that half of the participants (49.1\%) reported they would not choose to be on a nursing course if given a choice, $45.4 \%$ thought of not going into the nursing profession in the future, and $23.7 \%$ considered entering a healthcare industry that has zero contact with patients [38]. Ulupınar \& Aydogan [39] found that $42.5 \%(n=428)$ of new graduate nurses in the first years of their career had considered leaving nursing. In Sweden, $10-$ $20 \%$ of fresh graduates have considered leaving the profession [15]. In the Arabic counties, no studies were found regarding the intention to leave among undergraduates. The findings of this study are unfortunate, students reported a higher percentage of not viewing nursing as a lifelong career before actually starting to practice nursing than those in previous studies who intended to leave after being employed. Students are expected to have the desire to pursue their dream and study their major based on their preferences. Academic and clinical stress, poor academic performance [40], low satisfaction about their field of study [41], changes in health [42], low resilience [43], online learning [44], unrealistic job expectations, poor work conditions, demands exceeding resources, increased work hazards, insufficient autonomy, and control over practice $[45,46,47,48]$. These all considered reasons behind nursing students' intention to leave nursing profession in Palestine.

The results also showed that male nursing students have higher resilience compared to females. The survey findings are in tandem with findings of previous research [24,49]. Boardman et al., [50] found that the heritability of resilience is higher among men than women. This implies that genetic factors play an essential role in heritable resilience to environmental stressors, as mediated by more proximate measures of psychological functioning. This study demonstrates that gender differences in resilience factors are influenced by the idea that men and women have unique personality traits that influence how they cope with adversity. For instance, in Arabic countries, men tend to communicate less and are taught to suppress their emotions during adversity as they receive less help and empathy than women who express more and earn more empathy and other forms of support. In addition, women are more likely to rely on familial and community protective factors, while men depend more on individual protective factors [51]. 
In this study, students who were working parallel to their nursing studies had higher resilience. Discussion on workers' work-life balance has been ongoing since the 1980s. Maintaining a good work and life balance is one of the progressing issues academics face in higher education institutions [52]. Ching \& Cheung [53] found that having a paid job predicted resilience. Working aids in developing resilience by fostering competence in the face of, and professional growth following, workplace adversity [54]. In addition, students who exercise/ play sports had higher resilience, and lower burnout than those who do not exercise/play sports. Many studies have found that physical activity/exercise is one frequently mentioned factor for promoting resilience [55, 56]. The healthy weight of physical activity on resilience can be attributed to that it can induce positive physiological and psychological improvements, guard against the effects of stressful events, and minimize several neurological diseases [57]. Students who live on campus had higher resilience; this finding was consistent with the study by Dawson \& Pooley [58], which revealed that perceived parental autonomy support in first-year university students was associated with higher resilience. Perceived parental autonomy support enables students to rely on themselves, make their own decisions, encouraging them to explore, find, and decide based on their interests, values, and goals, which develops resilience.

The results also revealed that students who did not receive support from family and friends had higher burnout. Studies have shown that individuals can redefine a problematic situation as less threatening when they perceive a high level of support from their social network and regulate emotions like mistrust, anxiety, and fear more effectively [59]. A meta-analysis of 19 studies and 95,434 participants established that social support was negatively correlated with student burnout [60]. Therefore, receiving support from society is crucial for university students as it affects their motivation towards study.

Students who smoke had higher burnout compared to those who did not. Similarly, Kinnunen et al., [61] in their study found that daily smoking was most common among those who had a high level of school burnout, and the stress and coping model of substance use proposes that people with more stress, feelings of distress, and a lack of other coping resources (e.g., social support) may smoke cigarettes to cope with stress [62].

The study's findings revealed that students at higher academic levels (3rd and 4th year) have higher burnout than those in their first and second years. The results were in harmony with the longitudinal study by Rudman \& Gustavsson, [35] which found an increase in study burnout (from 30-41\%) across three years in higher education, and levels of both exhaustion and disengagement increased significantly across the years in education ( $p<0.001)$. Similarly, Quina Galdino et al. [32] found that the more advanced the school year, the higher the exhaustion $(p=0.003)$, depersonalization ( $<<0.001)$, and low academic effectiveness $(p=0.012)$ scores. This finding may be correlated to the fact that students at higher educational levels have advanced subjects, higher practical workload, and are challenged to experience activities as nurses in training in the internship field. Besides, the proximity to the completion of the course brings uncertainties, doubts, and concerns regarding insertion in the labor market, approval in selective processes, and expectations regarding professional success.

The results revealed that students with lower GPAs, studying an hour or less daily, and studying a day or less before the exam, have higher burnout. In comparison, students who study a week or more before the exam have higher resilience. Rahmatpour et al., [63] similarly revealed in his study on 303 students at the Guilan University of Medical Sciences that lower GPA $(\beta=-1.17, P=0.002)$, Students with less interest in their field of study $(\beta=-0.42, P=0.000)$, Students who postponed their studies to latter days of semester which are close to examinations $(\beta=0.22, P=0.000)$ were associated with higher academic burnout. In addition, Lee et al., [64] study showed that students with higher GPAs have more self-confidence and experience less academic burnout. Furthermore, postponing studying to the exam day can cause the student to become more stressed and more academic burnout.

\section{Conclusion}

It's widely acknowledged that a growing nursing shortage is on the horizon. The alarming rate of burnout among nurses around the world is contributing to this shortage. The rigor of nursing education has contributed to a significant problem in student attrition and burnout. Internationally little research was done to examine resilience and burnout in nursing students, and no studies examined these variables in nursing students in Arabic counties were found.

In this study, the participants had moderate levels of resilience and burnout. The result of the analysis revealed a negative correlation between resilience and burnout. The study found that almost half of the students were not satisfied when they joined the nursing program, and half of the students intend to leave nursing profession in future. In this study, higher resilience was associated with male gender, wanted to study nursing, playing exercise/sports, working, living on campus/ dorm, receiving support from friends and family, intend to stay in nursing profession, and studying before a week or more of the exam. Whereas, not receiving support from family \& friends, not exercising, smoking, intention to leave nursing profession in future, higher academic year, lower GPAs, studying an hour or less on a daily basis, and studying a day or less of the exam were all associated with higher burnout.

Without any questions, previous research indicated that resilience is important attribute for nurses and nursing students alike. Based on this research, resilience in baccalaureate nursing students might play an important role in decreasing nursing shortage by enhancing overall success and decreasing future burnout and intention to leave.

\section{Abbreviations}

\section{CD-RISC 10}

The Connor-Davidson Resilience Scale.

ProQol5

The Professional Quality of Life Scale Version 5.

GPA

Grade Point Average.

\section{Declarations}




\section{Authors' contributions}

ZS contributed to the design of the study, data collection, conduct and analyses of the research, data interpretation, and drafted the manuscript. AS

contributed to the data interpretation and critically revised the manuscript. Both authors read and approved the final manuscript.

\section{Ethics approval and consent to participate}

Institutional Review Board approvals were obtained from An-najah National University prior to data collection. No foreseeable risks were associated with this research project. Completion of the survey constituted as informed consent, and no identifiable information was included in the survey (Anonymity). The data was kept anonymous and confidential during all stages of the data processing and write up.

\section{Consent for publication}

Not applicable.

\section{Availability of data and materials}

The datasets used and/or analyzed during the current study are available from the corresponding author on reasonable request.

\section{Competing interests}

Not applicable.

\section{Funding}

Not applicable.

\section{Authors' contributions}

ZS conducted the study, collected the data, analyzed and interpreted the findings and drafted this manuscript. AS supervised the study analysis, interpretation of findings, and made substantive intellectual contributions to the manuscript. All authors read and approved the final manuscript.

\section{Acknowledgments}

Special thanks to the Three Palestinian Universitates for their efforts in distributing the online survey on their university portals.

\section{Authors' information}

Corresponding Author: Zareefa shaabna, Community Mental Health Nursing, Birzeit University, Birzeit, Palestine. Zareefa14@yahoo.com

Contributing author: Adnan Sarhan, Community Mental Health Nursing, AN-Najah National University, Nablus, Palestine. asarhan@najah.edu

\section{References}

1. Adriaenssens J, De Gucht V, Maes S. Determinants and prevalence of burnout in emergency nurses: A systematic review of 25 years of research. International Journal of Nursing Studies. 2015 Feb;52(2):649-61.

2. Lima da Silva JL, Campos Dias A, Reis Teixeira L. Discussion on the Burnout Syndrome: Its Causes and Implications for the Health of Nursing Personnel. Aquichan. 2012 Aug 1;12(2):144-59.

3. Maslach C, Leiter MP. Understanding the burnout experience: recent research and its implications for psychiatry. World Psychiatry [Internet]. 2016 Jun;15(2):103-11. Available from: https://www.ncbi.nlm.nih.gov/pmc/articles/PMC4911781/

4. De A, Christiane K, Silveira D, Cavalcanti N, Barbosa Da Silva D, Pitt De Almeida M, et al. BURNOUT SYNDROME AMONG UNDERGRADUATE NURSING STUDENTS IN PUBLIC UNIVERSITIES. Journal of Nursing [Internet]. 2014; Available from: https://periodicos.ufpe.br/revistas/revistaenfermagem/article/download/10107/10577

5. da Silva RM, Goulart CT, Lopes LFD, Serrano PM, Costa ALS, de Azevedo Guido L. Hardy personality and burnout syndrome among nursing students in three Brazilian universities-an analytic study. BMC Nursing. 2014 Mar 30;13(1).

6. Ferri P, Guerra E, Marcheselli L, Cunico L, Di Lorenzo R. Empathy and burnout: an analytic cross-sectional study among nurses and nursing students. Acta Bio-Medica: Atenei Parmensis [Internet]. 2015 Sep 9;86 Suppl 2:104-15. Available from: https://pubmed.ncbi.nlm.nih.gov/26629665/

7. Dyrbye LN, West CP, Satele D, Boone S, Tan L, Sloan J, et al. Burnout Among U.S. Medical Students, Residents, and Early Career Physicians Relative to the General U.S. Population. Academic Medicine. 2014 Mar;89(3):443-51.

8. Dyrbye L, Shanafelt T. A narrative review on burnout experienced by medical students and residents. Medical Education. 2015 Dec 23;50(1):132-49.

9. Jackson ER, Shanafelt TD, Hasan O, Satele DV, Dyrbye LN. Burnout and Alcohol Abuse/Dependence Among U.S. Medical Students. Academic Medicine. 2016 Sep;91(9):1251-6.

10. Kovner CT, Brewer CS, Fatehi F, Jun J. What does nurse turnover rate mean and what is the rate? Policy, politics \& nursing practice [Internet]. 2014;15(34):64-71. Available from: https://www.ncbi.nlm.nih.gov/pubmed/25156041 
11. Almazan JU, Albougami AS, Alamri MS. Exploring nurses' work-related stress in an acute care hospital in KSA. Journal of Taibah University Medical Sciences [Internet]. 2019 Aug 1;14(4):376-82. Available from: https://www.sciencedirect.com/science/article/pii/S1658361219300757

12. Zaheer S, Ginsburg L, Wong HJ, Thomson K, Bain L, Wulffhart Z. Turnover intention of hospital staff in Ontario, Canada: exploring the role of frontline supervisors, teamwork, and mindful organizing. Human Resources for Health. 2019 Aug 14;17(1).

13. Hämmig O. Explaining burnout and the intention to leave the profession among health professionals - a cross-sectional study in a hospital setting in Switzerland. BMC Health Services Research. 2018 Oct 19;18(1).

14. Lee MMD, Gensimore MM, Maduro RS, Morgan MK, Zimbro KS. The Impact of Burnout on Emergency Nurses' Intent to Leave: A Cross-Sectional Survey. Journal of Emergency Nursing. 2021 Aug.

15. Rudman A, Omne-Pontén M, Wallin L, Gustavsson PJ. Monitoring the newly qualified nurses in Sweden: the Longitudinal Analysis of Nursing Education (LANE) study. Human Resources for Health. 2010 Apr 27;8(1).

16. Kovner CT, Djukic M. The Nursing Career Process From Application Through the First 2 Years of Employment. Journal of Professional Nursing. 2009 Jul;25(4):197-203.

17. Kim J, Chae D, Yoo JY. Reasons Behind Generation Z Nursing Students' Intentions to Leave their Profession: A Cross-Sectional Study. INQUIRY: The Journal of Health Care Organization, Provision, and Financing. 2021 Jan; 58:004695802199992.

18. ATKINSON PA, MARTIN CR, RANKIN J. Resilience revisited. Journal of Psychiatric and Mental Health Nursing [Internet]. 2009 Mar;16(2):137-45. Available from: https://onlinelibrary.wiley.com/doi/full/10.1111/j.1365-2850.2008.01341.x

19. Schetter CD, Dolbier C. Resilience in the Context of Chronic Stress and Health in Adults. Social and Personality Psychology Compass. 2011 Sep;5(9):63452.

20. Cyrulnik B. Resilience: how your inner strength can set you free from the past. New York: Mjf Books; 2011.

21. Fleming J, Ledogar RJ. Resilience, an Evolving Concept: A Review of Literature Relevant to Aboriginal Research. Pimatisiwin [Internet]. 2008 [cited 2022 Jan 29];6(2):7-23. Available from: https://www.ncbi.nlm.nih.gov/pmc/articles/PMC2956753/\#

22. Stephens TM. Nursing Student Resilience: A Concept Clarification. Nursing Forum. 2013 Apr;48(2):125-33.

23. Guo Y, Luo Y, Lam L, Cross W, Plummer V, Zhang J. Burnout and its association with resilience in nurses: A cross-sectional study. Journal of Clinical Nursing [Internet]. 2017 Sep 4;27(1-2):441-9. Available from: https://onlinelibrary.wiley.com/doi/full/10.1111/jocn.13952

24. Alameddine M, Bou-Karroum K, Ghalayini W, Abiad F. Investigating the Resilience of Nurses During the COVID-19 Pandemic A Cross-Sectional Survey from Lebanon. 2021 Feb 10.

25. Kutluturkan S, Sozeri E, Uysal N, Bay F. Resilience and burnout status among nurses working in oncology. Annals of General Psychiatry. 2016 Nov 14;15(1).

26. Mathad MD. Correlates and Predictors of Resilience among Baccalaureate Nursing Students. JOURNAL OF CLINICAL AND DIAGNOSTIC RESEARCH. 2017.

27. Chamberlain D, Williams A, Stanley D, Mellor P, Cross W, Siegloff L. Dispositional mindfulness and employment status as predictors of resilience in third year nursing students: a quantitative study. Nursing Open. 2016 Jun 2;3(4):212-21.

28. Grande RAN, Berdida DJE, Villagracia HN, Cornejo LTO, Villacorte LM, Borja MaVF. Association Between Perceived Resilience and Mental Well-Being of Saudi Nursing Students During COVID-19 Pandemic: A Cross-Sectional Study. Journal of Holistic Nursing. 2021 Apr 20;089801012110090.

29. Metwally Elsayed M, Abd-Elfatah Abd-Elhamid E, Ahmed Mohsen H, Abd El-Gawad Mousa M. Creativity, Resilience and Sense of Humor among Nursing Graduates, Alexandria University, Egypt. Egyptian Journal of Health Care [Internet]. 2020 Sep 1 [cited 2021 Aug 25];11(3):541-58. Available from: https://ejhc.journals.ekb.eg/article_148843.html

30. Abram MD, Jacobowitz W. Resilience and Burnout in Healthcare Students and Inpatient Psychiatric Nurses: A Between-Groups Study of Two Populations. Archives of Psychiatric Nursing. 2020 Oct;

31. Lopes AR, Nihei OK. Burnout among nursing students: predictors and association with empathy and self-efficacy. Revista Brasileira de Enfermagem. 2020;73(1).

32. Quina Galdino MJ, Brando Matos de Almeida LP, Ferreira Rigonatti da Silva L, Cremer E, Rolim Scholze A, Trevisan Martins J, et al. Burnout among nursing students: a mixed method study. Investigación y Educación en Enfermería. 2020 Feb 26;38(1).

33. Alshawish E, Nairat E. Burnout and psychological distress among nurses working in primary health care clinics in West Bank-Palestine. International Journal of Mental Health. 2020 Apr 22;1-15.

34. Al Barmawi MA, Subih M, Salameh O, Sayyah Yousef Sayyah N, Shoqirat N, Abdel-Azeez Eid Abu Jebbeh R. Coping strategies as moderating factors to compassion fatigue among critical care nurses. Brain and Behavior. 2019 Mar 18;9(4): e01264.

35. Rudman A, Gustavsson JP. Burnout during nursing education predicts lower occupational preparedness and future clinical performance: A longitudinal study. International Journal of Nursing Studies. 2012 Aug;49(8):988-1001.

36. Rees CS, Heritage B, Osseiran-Moisson R, Chamberlain D, Cusack L, Anderson J, et al. Can We Predict Burnout among Student Nurses? An Exploration of the ICWR-1 Model of Individual Psychological Resilience. Frontiers in Psychology. 2016 Jul 19;7.

37. Flinkman M, Leino-Kilpi H, Salanterä S. Nurses' intention to leave the profession: integrative review. Journal of Advanced Nursing. 2010 May 21;66(7):1422-34.

38. Lin Y, Hu Z, Danaee M, Alias H, Wong LP. The Impact of the COVID-19 Pandemic on Future Nursing Career Turnover Intention Among Nursing Students. Risk Management and Healthcare Policy [Internet]. 2021 Aug 27 [cited 2021 Sep 20]; 14:3605-15. Available from: https://www.ncbi.nlm.nih.gov/pmc/articles/PMC8407786/

Page 8/9 
39. Ulupınar S, Aydogan Y. New Graduate Nurses' Satisfaction, Adaptation and Intention to Leave in Their First Year: A Descriptive Study. Journal of Nursing Management. 2021 Feb 27;

40. Dube MB, Mlotshwa PR. Factors influencing enrolled nursing students' academic performance at a selected private nursing education institution in KwaZulu-Natal. Curationis. 2018 Aug 28;41(1).

41. Hakim A. Nursing students' satisfaction about their field of study. Journal of advances in medical education \& professionalism [Internet]. 2014 [cited 2020 Jan 3];2(2):82-7. Available from: https://www.ncbi.nlm.nih.gov/pmc/articles/PMC4235554/

42. Olvera Alvarez HA, Provencio-Vasquez E, Slavich GM, Laurent JGC, Browning M, McKee-Lopez G, et al. Stress and Health in Nursing Students. Nursing Research [Internet]. 2019 [cited 2020 Feb 10];68(6):453-63. Available from: https://journals.Iww.com/nursingresearchonline/fulltext/2019/11000/Stress_and_Health_in_Nursing_Students_The_Nurse.6.aspx

43. CHOW KM, TANG WKF, CHAN WHC, SIT WHJ, CHOI KC, CHAN S. Resilience and well-being of university nursing students in Hong Kong: a cross-sectional study. BMC Medical Education. 2018 Jan 12;18(1).

44. Masha'al D, Rababa M, Shahrour G. Distance Learning-Related Stress Among Undergraduate Nursing Students During the COVID-19 Pandemic. Journal of Nursing Education. 2020 Dec 1;59(12):666-74.

45. Jawabreh BAR. Burnout and the Intention to Leave among Oncology Hematology Nurses in Palestinian Hospitals. [Al- Quds University]; 2016.

46. Palestinian National Institute of Public Health (PNIPH). National Human Resources for Health Observatory: Mapping the Palestinian Health Workforce [Internet]. 2019. Available from: https://www.scirp.org/\%28S\%28vtj3fa45qm1 ean45vvffcz55\%29\%29/reference/referencespapers.aspx? referenceid $=2772106$

47. Hamdan M, Hamra AA. Burnout among workers in emergency Departments in Palestinian hospitals: prevalence and associated factors. BMC Health Services Research [Internet]. 2017 Jun 15;17(1). Available from: https://bmchealthservres.biomedcentral.com/articles/10.1186/s12913-017-2356-3

48. Abukhader I, Abukhader K, Naser O, Saeed Y, Maliashe A. Burnout among Palestinian Nurses Working in Governmental and Private Hospitals at Nablus District. Open Journal of Social Sciences [Internet]. 2020;08(07):1-11. Available from: https://www.scirp.org/journal/paperinformation.aspx? paperid $=101306$

49. Aloba O, Olabisi O, Aloba T. The 10-Item Connor-Davidson Resilience Scale. Journal of the American Psychiatric Nurses Association. 2016 Jan;22(1):4351.

50. Boardman JD, Blalock CL, Button TMM. Sex Differences in the Heritability of Resilience. Twin research and human genetics: the official journal of the International Society for Twin Studies [Internet]. 2008 Feb 1 [cited 2020 Oct 4];11(1):12-27. Available from: https://www.ncbi.nlm.nih.gov/pmc/articles/PMC2674367/

51. Sun J, Stewart D. Age and Gender Effects on Resilience in Children and Adolescents. International Journal of Mental Health Promotion. 2007 Nov;9(4):16-25.

52. Kinman G, Jones F. A Life Beyond Work? Job Demands, Work-Life Balance, and Wellbeing in UK Academics. Journal of Human Behavior in the Social Environment. 2008 Jun;17(1-2):41-60.

53. Ching SSY, Cheung K. Factors Affecting Resilience of Nursing, Optometry, Radiography and Medical Laboratory Science Students. International Journal of Environmental Research and Public Health. 2021 Apr 7;18(8):3867.

54. Caza BB, Milton LP. Resilience at Work. Oxford Handbooks Online. Oxford University Press; 2011.

55. Wu G, Feder A, Cohen H, Kim JJ, Calderon S, Charney DS, et al. Understanding resilience. Frontiers in Behavioral Neuroscience [Internet]. 2013;7. Available from: https://www.ncbi.nlm.nih.gov/pmc/articles/PMC3573269/

56. McEwen BS. In pursuit of resilience: stress, epigenetics, and brain plasticity. Annals of the New York Academy of Sciences. 2016 Feb 25;1373(1):56-64.

57. Arida RM, Teixeira Machado L. The Contribution of Physical Exercise to Brain Resilience. 2020 [cited 2021 Jul 10];14. Available from: https://app.dimensions.ai/details/publication/pub.1134708016?

search_mode=content\&search_text=Resilience\&search_type=kws\&search_field=full_search\&or_facet_year=2021\&or_facet_year=2020\&or_facet_year=2019

58. Dawson M, Pooley JA. Resilience: The Role of Optimism, Perceived Parental Autonomy Support and Perceived Social Support in First Year University Students. Journal of Education and Training Studies. 2013 May 7;1(2).

59. Sippel LM, Pietrzak RH, Charney DS, Mayes LC, Southwick SM. How does social support enhance resilience in the trauma-exposed individual? Ecology and Society. 2015;20(4).

60. Kim B, Jee S, Lee J, An S, Lee SM. Relationships between social support and student burnout: A meta-analytic approach. Stress and Health. 2017 Jun 22;34(1):127-34.

61. Kinnunen JM, Lindfors P, Rimpelä A, Salmela-Aro K, Rathmann K, Perelman J, et al. Academic well-being and smoking among 14- to 17-year-old schoolchildren in six European cities. Journal of Adolescence [Internet]. $2016 \mathrm{Jul}$; 50:56-64. Available from: https://www.sciencedirect.com/science/article/pii/S0140197116300227

62. Wills TA, Cleary SD. How are social support effects mediated? A test with parental support and adolescent substance use. Journal of Personality and Social Psychology. 1996;71(5):937-52.

63. Rahmatpour P, Chehrzad M, Ghanbari A, Sadat-Ebrahimi S-R. Academic burnout as an educational complication and promotion barrier among undergraduate students: A cross-sectional study. Journal of Education and Health Promotion [Internet]. 2019 [cited 2021 Apr 29]; 8:201. Available from: https://pubmed.ncbi.nlm.nih.gov/31807591/

64. Lee J, Puig A, Kim Y-B, Shin H, Lee JH, Lee SM. Academic burnout profiles in Korean adolescents. Stress and Health. 2010 Nov 29;26(5):404-16. 